University of Michigan Law School University of Michigan Law School Scholarship Repository

1994

\title{
Discovery Cost Allocation: Comment on Cooter and Rubinfeld
}

Edward H. Cooper

University of Michigan Law School, coopere@umich.edu

Available at: https://repository.law.umich.edu/articles/555

Follow this and additional works at: https://repository.law.umich.edu/articles

Part of the Civil Procedure Commons, and the Litigation Commons

\section{Recommended Citation}

Cooper, Edward H. "Discovery Cost Allocation: Comment on Cooter and Rubinfeld." J. Legal Stud. 23, no. 2 (1994): 465-80.

This Article is brought to you for free and open access by the Faculty Scholarship at University of Michigan Law School Scholarship Repository. It has been accepted for inclusion in Articles by an authorized administrator of University of Michigan Law School Scholarship Repository. For more information, please contact mlaw.repository@umich.edu. 


\title{
DISCOVERY COST ALLOCATION: COMMENT ON COOTER AND RUBINFELD
}

\author{
EDWARD H. COOPER*
}

\section{INTRODUCTION}

$\mathrm{D}$ ISCOVERY practice continues to be the single most troubling element of contemporary procedure. To be sure, the system seems to work well in a high proportion of all federal cases. The proportion may seem astonishingly high in relation to the amount of attention devoted to discovery. The discovery problems that occur in a relatively small proportion of the federal caseload, however, impose serious burdens on the parties and the court system. Every proposal that addresses discovery "abuse" deserves serious attention. These comments focus on the discovery abuse portion of the paper by Cooter and Rubinfeld. Questions are posed that may have persuasive answers. Whether or not there are persuasive answers, the paper is a great success because it forces consideration and reconsideration of the very nature of discovery. Much can be learned by grappling with this proposal.

The dilemma of discovery reform can be introduced by remembering Civil Rule 1. The Rules are construed and applied "to secure the just, speedy, and inexpensive determination of every action." We want justice. But we know that we must reconcile our desire for justice with the need to get lawsuits decided, and decided without undue delay or expense. We hope discovery makes results more just. We believe, and have been given an elegant model to demonstrate, that discovery can promote settlement. We know it can often increase delay and expense. We cannot really know whether the present system achieves a better blend of cost with justice by judgment and settlement than might be achieved by a

\footnotetext{
* Thomas M. Cooley Professor of Law, University of Michigan. Presented at the John M. Olin Program in Law and Economics Conference on "Economic Analysis of Civil Procedure"' at the University of Virginia School of Law, March 26-27, 1993.

[Journal of Legal Studies, vol. XXIII (January 1994)]

(C) 1994 by The University of Chicago. All rights reserved. 0047-2530/94/2301-0018\$01.50
} 
dramatically different system. A system with no discovery, more trials, and less settlement might be better. Most reform discussion, however, is set in the framework of more modest proposals. Proposals to shift the costs of discovery fit into this mold.

The problem of excessive discovery seems reasonably straightforward. Discovery rules are designed to enable a party to force others, parties and nonparties, to disclose information. The inquiring party does not bear all the costs of the process. The costs of responding, which include interpreting the demand, gathering the information, and formulating and delivering a response, are borne by the responding party. In addition, the opportunity to seek information that need not be disclosed at trial encourages pursuit of information that would not be sought at trial for fear of unfavorable surprise. The first question is why the inquiring party should not have to bear all the costs of responding. What makes it fair to compel an opposing party, or a nonparty, to bear a cost of providing information it might choose to produce at trial or not to produce at all? This question has been answered by evolution of the adversary system, not articulated principle. If a different answer had been given-if the inquiring party were required to shoulder all the costs of compliance, including the time costs-the discovery problem would be much different.

The question of "abuse" arises when part of the cost is borne by the person responding. In approaching this question, it may help to recognize that much untoward discovery results from ineptness, not some darker motive. It seems fair to assert that much discovery is conducted by people who are not trial litigators. They have little sense of the realistic needs of trial, nor of the manageable possibilities of trial. The discussion may be helped by distinguishing among "overuse" resulting from the opportunity to ask questions without bearing the cost of response, inept "misuse," and malevolent "abuse." By far the most important question raised by this exchange is whether the costs of discovery compliance should be reallocated in order to reduce overuse.

If some reason is found for insisting that a person responding to discovery should bear part of the response cost, the division of costs can be made only by articulating a theory of allocation. There is a certain abstract charm to the theory that the requesting party should be free to demand discovery up to the point at which the cost of compliance equals the expected value to the requesting party. At least if adjustment is made for the costs of demanding and evaluating the response, a system that equates the marginal cost of discovery with the marginal benefit seems sensible enough. But the reason for allocating part of the cost to a party who benefits and part to another person who gains no benefit, and may 
be harmed, remains to be identified. Shifting from the abstract formula to implementation, moreover, leads to several obvious problems.

One major part of the problem is the nature of discovery: the demanding party often has no idea what to expect. All that is possible is comparison across some universe of cases with some degree of abstract similarity to this case. A question about inspection practices, for example, may have an expected yield of $X$ in all tort cases, $2 X$ in all product liability cases, and $4 X$ in "foreign-object-in-the-bottle" product liability cases. The value in a specific case cannot be known until the question is answered. Setting a value after discovery is almost as difficult. The actual value of information will depend on many factors, including the relative astuteness of the person who gains it.

A deeper part of the problem is to find a theory that explains why the responding person should be expected to invest more in producing information that is more valuable to its adversary or to one or more parties in litigation between strangers.

The problems are sufficient that the "abuse" formulation is apparently abandoned when it comes time to suggest an actual rule for reallocating discovery costs. Instead, the parties are to share equally the cost of all reasonable discovery. If compliance costs are $\$ 1,000$ for plaintiff and $\$ 2,000$ for defendant, each bears $\$ 1,500$. Each also would bear $\$ 1,500$ if compliance costs were $\$ 2,000$ for plaintiff and $\$ 1,000$ for defendant. The figure that represents half the total cost of reasonable discovery by both parties (here $\$ 1,500$ ), $\alpha$, is designated as the "shifting point." The demanding party pays all compliance costs for additional discovery once the costs of the responding party reach the shifting point. This result might be justified in several ways. One would be an abstract assertion that it is "fair" to allocate evenly the costs of discovery, even if no other costs are allocated evenly. Another is the justification offered here: even allocation achieves symmetry of discovery costs, easing the way toward a settlement that corresponds to the "correct" trial judgment.

Problems remain with this alternative. I have reacted to the cost allocation proposal from a pragmatic perspective, asking whether it should be incorporated in the Federal Rules of Civil Procedure. My reactions have been those of an academic lawyer, imagining the difficulties of drafting and implementing a new rule. It is difficult to array in an entirely coherent order the welter of difficulties that bubble to the surface. They can be grouped, however, in three rough categories. First come the practical difficulties. Second come theoretical doubts about the wisdom of the allocation, addressed more or less in its own terms. Finally come reflections on the questions the proposal raises as to the nature and purpose of discovery in an adversary trial system. These categories cannot be 
separated neatly. The discussion of each will overlap and anticipate or reflect the discussion of the others. An approximate separation may help nonetheless.

\section{Difficulties of Implementation}

Implementation of this discovery cost allocation proposal must overcome many difficulties. Workaday procedural rules often must forgo intellectually compelling models because the costs of administration overcome the theoretical advantages. The nature of the difficulties that will be encountered by this theoretical model is illustrated by the following partial list of questions.

How is a court to measure the total cost of complying with the discovery reasonably needed by each side? If not by measuring anticipated costs of response and anticipated benefits for this case, but by "average values for similar cases in the past," categories of similarity must be identified. But how is similarity to be identified? One dimension is need for the information. Is this measured by the nature of the issues? By the extent of information available to each party before discovery is undertaken? By the costs of acquiring information by other means? By the stakes? By the probability of success-the anticipated value of information bearing on damages increases as the probability of liability increases? It would be costly beyond any reasonable measure to assess need along these and other dimensions on a case-by-case basis. The most that could be done would be to adopt very crude measures of similarity that would group quite unlike cases together because they involved some dimension of similarity. One example might be actions claiming negligent infliction of bodily injury by operating an automobile. The example might be refined by categories of injury, number and difficulty of the theories of negligence, the presence of multiple parties or claims, and so on. However refined, the categories would cover cases that in fact had quite different reasonable needs for discovery.

The problem of categorization is the same as to compliance cost. That will vary according to the amount of information already gathered, whether for this litigation, other litigation, or nonlitigation purposes. It also will vary according to the ways in which the information is organized; the organization may, fortuitously, make it easier or more difficult to extract the relevant information. It also will vary with the efficiency and imagination of the people who retrieve it and with the value of their time. All else being equal, this would suggest that the total cost of reasonable discovery will depend on the identity of the litigants as well as the nature of the case. Compare two drug manufacturers. One maintains 
complete and carefully indexed records concerning raw materials, manufacturing, inspection, and distribution that allow it to follow the complete course of each production batch from beginning to the point of final sale. The other, making the same product, has indifferent records scattered among various plants and departments. The cost of complying with reasonable discovery demands in the first product liability action brought against each will be dramatically different. Each, having been sued once, may consider the possibility of being sued again. The first may maintain in one place the fruits of discovery compliance, while the other returns the discovered materials as nearly as may be to their original sources. The cost of complying with reasonable discovery demands in the second action brought against each also would be dramatically different.

Administration of a discovery cost categorization system also must determine the time at which cases will be assigned to categories. Ongoing discovery may reveal at first less valuable information and then, perhaps because the earlier information has suggested other paths of inquiry and perhaps because the parties have been driven to more inventive inquiry, more valuable information. If the total cost of reasonable discovery and the derived shifting point are set at the outset, the shifting point may be reached before disclosure of the most important information.

The problem caused by setting the shifting point early in the litigation can be aggravated by party behavior. Unless the demanding party proceeds by very carefully planned and discrete steps, and also is very lucky, the responding party has an incentive to skew the progress of its responses. It should reveal the least useful information first, announce that the shifting point has been reached, and declare that compliance costs for all future responses must be carried by the demanding party.

The problem that the shifting point can be reached before the most important discovery is accomplished could be addressed by fixing a shifting point at the outset but allowing amendment as greater familiarity with the case supports more accurate determination. As discovery progresses, it may readily appear that the reasonable total level of discovery is greater than would have been predicted at the outset. The same result could be reached by not setting the shifting point until discovery has been completed. Either response entails great difficulties. The method of setting a shifting point at the outset, to be followed by adjustments, requires detailed judicial supervision. The burden of assessing the reasonable level of discovery will be great. The method of setting the shifting point after discovery has been completed would require as much judicial involvement and would invite decisions based on the actual fruits of discovery rather than reasonable anticipation. Perhaps more important, ex post determination of the shifting point leaves the parties without any guidance 
while conducting discovery. Uncertainty as to the allocation could readily destroy any leveling of the bargaining process that might result from the attempt to achieve symmetrical discovery costs.

Another problem is that of translating specific relief into dollar terms. For better or worse-for more or less guidance-it is commonly said that specific relief often is justified precisely because money cannot measure an important value. How do we measure the cost of reasonable discovery in a reapportionment action, a prison conditions case, or a suit to abate atmospheric pollution? If we are going to exempt such cases, one response will be to add claims for specific relief; perhaps that can be controlled effectively.

Finally, it is suggested at one point that the discovery cost allocation might be adjusted to reflect anticipated savings that result from avoiding the need to uncover the same information at trial. If the allocation system itself seems unworkable, this wrinkle is even more so.

\section{Difficulties of Assumption}

Beyond difficulties of implementation lie difficulties generated by the assumptions chosen to build the cost allocation model. Before attempting to move from model to implementation, it is necessary to ask whether adjustments must be made to reflect differences between these assumptions and the circumstances that may prevail-occasionally or often-in actual litigation.

The illustration is deliberately cast in terms of litigation in which the only stakes are money. It seems likely that there is not much litigation in which no party has any stake beyond the dollar level of the judgment. Few defendants are onetime litigators and uninsured. The contingent-fee system is held out as one way of financing litigation; it provides a repeat player in the lawyer who has future stakes. Even some disputes between uninsured onetime litigants are likely to have added stakes: to vindicate self-esteem, protect a reputation, punish an offender, and so on. We might respond by asserting that none of these interests should enter calculation of a reasonable level of discovery. A party who wants to pursue such interests should bear the full cost of discovery that goes beyond sharing the costs of reasonable discovery. This response may be persuasive in some settings, but it requires a value judgment that is not selfjustifying. At the least, it assumes that litigation is more concerned with transferring money than with protecting other values. At the extreme, it assumes that litigation is concerned only with transferring money in ways that achieve monetarily efficient compliance with efficient legal rules. The response is not persuasive if the legal system itself imposes future 
stakes. A sufficient illustration is provided by nonmutual preclusion. If a party's defeat will preclude relitigation of common issues in reasonably anticipated future litigation, that party must behave as if the stakes include the future litigation. At the very least, it is reasonable to engage in more extensive preparation, including more extensive discovery. The allocation of discovery costs between a party whose only stake is the judgment in the present action and a party who perforce has higher stakes requires independent justification. Perhaps the conclusion should be that all incremental discovery costs of all parties should be imposed on the party who fears future preclusion. The conclusion cannot be justified, however, on any theory that this party is behaving in an unreasonable fashion. The discovery costs can be entirely rational in relation to the real stakes. The conclusion also must face another peril of nonmutual preclusion. Having won the first action, the common party often cannot be confident that defeat in a second action will not support nonmutual preclusion in a third action; it may have to endure yet again the burden of litigation involving future preclusion stakes.

Quite apart from the troubling questions about discovery that affects future litigation, the fact remains that there is likely to be little litigation in which all parties have only present stakes. This means that there will be very little litigation that can provide models of money-stakes-only reasonable discovery costs. At least as important, it will be virtually impossible to identify which other actions satisfy this requirement. Experience cannot afford a reliable guide on the reasonable level of discovery actually pursued by the parties in litigation with no future stakes.

Reliance on a money-stakes-only model may encounter another difficulty. It is assumed that there is no intrinsic value in achieving results that come closer to the "right" decision. Spending $\$ 100$ to achieve a $\$ 50$ increase in accuracy is a waste. There is no need to argue the question now; it is enough to observe that disagreement on this score would end the discussion.

There also may be a puzzle in a different direction. The definition of abuse assumes that it is unreasonable to ask for discovery when compliance costs exceed the expected value. The concept of value may be complicated even in money-stakes-only litigation. A plaintiff may have a great need to discover the facts supporting a possible defense-it costs the defendant $\$ 100$ to produce information that increases the plaintiff's pessimism and reduces the expected value of the claim by $\$ 500$ or, conceivably, to zero. The same is true of discovery that persuades the defendant that the claim is stronger than the defendant had believed. This phenomenon can be accommodated in the "abuse" model by recognizing that it is valuable to reduce uncertainty. Assigning a value, however, 
must be in some measure arbitrary. The phenomenon may be accommodated more easily in a cost-sharing model, so long as it is assumed that the total cost of reasonable discovery has been set accurately.

Discovery reaches nonparties as well as parties. Concern with preserving symmetry of discovery costs between the parties would suggest that they share equally the reasonable party costs of third-party discovery but that the unconcerned third party bear all of its compliance costs. That result would permit much discovery that produces benefits for all parties well below nonparty compliance costs. In addition, exempting third-party discovery from cost allocation rules would drive some discovery away from more efficient party discovery and toward less efficient third-party discovery. And in any event, it may seem bizarre to allow one party to recover part-and beyond the shifting point all-of its compliance costs but to deny any protection to nonparties.

An attempt to transfer nonparty compliance costs to the parties, so that the parties do not exact compliance costs greater than the benefits they realize, must find a theory of allocation. Equal allocation would present severe difficulties, whether undertaken in an effort to preserve cost symmetry or for some other reason. The information frequently is more valuable to one party than another. It is tempting to treat third-party discovery as the responsibility of the party who initiates the discovery. This response is not convincing, however, since often both parties need the information and each has access to the discovered information. No one may be confident in predicting which party will gain more from the information, and even confident predictions may go astray. Nonetheless, there may be a temptation to impose the cost on the party that makes the discovery request. Some practicing lawyers are reporting even now that amended Civil Rule 45 is being used by nonparties to seek protection against disclosing materials gathered in response to discovery subpoenas until the demanding party has paid the compliance costs.

A deeper problem is that of trial preparation outside of discovery. Before modern discovery methods were available, it was expected that each party would bear its own costs of preparing for trial. Even now, there is much preparation apart from discovery. The preparation involves both seeking information from others and marshaling the information within the litigants' own living and archival memories. The costs of discovery cannot be addressed apart from these costs. One reason is that rules regarding discovery costs will affect the balance between discovery and other modes of preparation. Another, and more important, reason is that the value of discovery and the cost of compliance will depend on the actual use and benefits of independent preparation. A party that has prepared carefully on its own account may be able to respond to discov- 
ery rapidly and at low cost. The well-prepared party also is likely to engage in less discovery and may benefit less from the information it obtains. A party that has delayed preparation may find it expensive to respond. The expense may not be a true measure of the cost of compliance, however, since the same expense might have been incurred at a later time in preparation for a more nearly imminent trial. In the same fashion, the dilatory party may benefit a great deal from discovering the information garnered by its better-prepared adversary; such benefit hardly seems occasion for raising the total level of reasonable discovery and the shifting point.

Yet another problem is that of changing allocation of discovery compliance costs in the context of the adversary system that has developed around the combination of modern discovery and other practices. The proposal would change the present system to shift part of discovery costs to the party whose reasonable needs for information entail greater compliance costs. In the illustration, and often in fact, that will be the plaintiff. Why require payment of this cost-win or lose-when the plaintiff is not obliged to pay many other defense costs?

Disclosure outside the demand-and-response mode of discovery raises further questions. In part, the questions go to the effect of voluntary disclosure. Information voluntarily disclosed may not have the same impact as information provided in response to discovery since there is no orderly sanction process to enhance reliability. It can make sense to use discovery to provide an official and at times binding confirmation of information previously disclosed by voluntary means. Discovery in this setting is in part informational and in part a means of tactical reassurance. How do we measure these costs and benefits? Is it important that the cost may depend on something as elusive as the degree of mutual trust among counsel and the parties?

Despite the general proposition that a party has an incentive to disclose information that would increase an adversary's pessimism, there also are strong incentives not to disclose some such information, particularly impeachment information that is more valuable if it appears as a surprise at trial. The cost of complying with discovery demands for such material may include the cost of protective discovery: before impeachment material is disclosed, the witness is deposed. Should compliance costs of this sort be treated in the same way as other costs?

Other disclosure questions are raised by the new Rule 26(a)(1) that requires voluntary disclosure as a prelude to discovery. Several districts have implemented such disclosure requirements by local rule even now. The duty to make disclosure is continuing. This changes the description of part of the compliance costs from discovery to disclosure. The change 
of description does not involve any change of substance. If costs of discovery compliance are to be shared, the costs of disclosure should be treated in the same way. The problem of separating preparation costs from compliance costs, however, is exacerbated by disclosure. The costs of disclosure must be incurred, moreover, unless the parties agree to forgo disclosure. The actual effectiveness of disclosure in reducing discovery costs - its value-is likely to vary substantially from case to case. Determining the reasonable level of discovery and its cost in relation to the reasonable cost and actual benefit of disclosure is likely to be difficult at the very best.

The purpose of allocating discovery costs so as to bring settlement closer to the expected value of a complete-information judgment makes one additional demand on the settlement process. The expected value of the discovery cost award becomes an element of bargaining. The effect is neutral only if all parties fulfill the conditions for efficient settlement as to this added element. Unless the shifting point is set with great accuracy, this result seems unlikely. Instead, the real need of one party to discover information after reaching the shifting point will defeat the attempt to attain symmetry of discovery costs.

An incidental question is raised by the assumption that an increase in discovery costs usually causes a decline in trial costs. That may often prove true, particularly when good litigators are at work. Discovery, however, can produce vast amounts of information. There is a temptation to use the information at trial. The same information often would not be sought at trial for fear of its unknown dimensions and because exploring the unknown is apt to take longer and prove more distracting. Judgments about the allocation of discovery costs may remain the same whether. discovery reduces or increases trial costs, but the matter at least must be resolved in its own terms.

\section{Broader Theoretical Questions}

Inevitably, any proposal for allocating the costs of adversary discovery focuses attention on the proper nature of the adversary system and the role of the discovery system in it.

\section{A. Litigation Costs in General}

We have a system that requires the parties to bear many of the costs of litigation. Allocation of these costs between the parties seems haphazard: the victor is awarded some part of the costs to an extent that depends on the nature of the litigation, while victor and vanquished each bear 
substantial portions of their own costs. At the same time, other costs are treated as public. The question of discovery costs could be approached most easily if we had an agreeable theory to distinguish private costs from public costs and to allocate private costs. Why should lawyers not be provided as a public service to any litigant who would rather trust a public lawyer than pay a private lawyer? Why should other costs of investigation and preparation not be paid according to the budget judgments of a public official? And so of discovery: Why should any part of the cost be carried by the parties, much less nonparties? There is something crude and almost offensive about rationing access to public dispute resolution by ability and willingness to pay, but we do it. If part of the cost is to be allocated to the parties, why not require the loser to pay all expenses of the victor? We have not even approached satisfactory answers to these questions. Any answer given to any part of the questions, such as apportioning the costs of discovery compliance, must be unsatisfactory accordingly.

Reaction to this problem may depend in part on the type of litigation. In typical personal injury tort litigation, we may well think that the costs of discovery compliance should be borne as a cost of doing business or a cost of liability insurance. Significant savings in transaction costs can be made by forgoing allocation. We may have similar reactions to many forms of civil rights litigation. Reactions are likely to be less uniform, however, with respect to other forms of litigation. What does intuition tell us about sharing or shifting the costs of discovery in business contract litigation? Antitrust litigation with a private plaintiff? Antitrust litigation with a public plaintiff? Private treble damages claims under the Racketeer Influenced and Corrupt Organizations Act?

\section{B. Purposes of Discovery}

The model assumes that discovery is designed to uncover previously unknown information. But it has a variety of purposes: one is to preserve evidence that is known to all parties. The need for this form of discovery may be difficult to compare across cases or even to predict in a particular case. Another purpose is to determine whether there is reason to sue; discovery for this purpose has a continuing legitimate role, as reflected in the 1993 amendments of Civil Rule 11. Discovery for this purpose may deserve different treatment. Discovery also may be designed to educate an adversary in a variety of ways: a deposition may make it easier to settle because it demonstrates that the adversary is unattractive as a witness, not because any information is revealed; simply asking for infor- 
mation may educate an adversary about the importance of theories that had been overlooked. It is not obvious that the cost of such discovery should be allocated by the same principles as other forms of discovery.

\section{Party Administration}

In many ways, the discovery process is designed to be implemented by the parties without need for judicial interference. The emphasis on forcing parties to work out discovery disputes for themselves is increasing. When party resolution fails and the district court must intervene, very deliberate decisions have been made to restrict opportunities for appellate review. Discovery is to be implemented by the parties first and the district courts second. Efforts to add new rules for allocating discovery costs are likely to increase the level of judicial supervision. It seems likely that detailed judicial supervision can be avoided, if at all, only by procedures that coerce cost allocation by agreement of the parties, who often do not have equal bargaining power, or that rely on quite general and correspondingly crude estimates of reasonable levels of discovery and reasonable costs of compliance.

\section{Discovery as Justice}

Disclosure of liability insurance coverage is required by Civil Rule 26(a)(1)(D). Despite the various purposes described in the Advisory Committee Note to former Rule 26(b)(2), the only plausible justification for such discovery is to enhance the fairness of settlement and the rationality of litigation. Insurance coverage often is the most important or even sole asset available to satisfy a judgment. Knowledge of coverage can be vitally important in determining the expected value of the judgment. It has nothing to do with the merits of the dispute. This aspect of discovery is not directly important to cost allocation proposals. The cost of disclosure ordinarily will be low. Discovery or disclosure of liability insurance is important because it seeks fairness in bargaining and provides an opportunity to set realistic limits on the amount spent preparing for trial. If discovery unabashedly pursues fairness in this dimension, perhaps there are other dimensions in which it should pursue fairness rather than one or another notions of efficiency.

\section{E. Work Product}

Work-product doctrine sets limits on discovery that seek to reconcile the cooperative character of discovery with the adversary character of trial. We deliberately deny discovery of material that could improve pre- 
dictions of the probable outcome. In part, this doctrine may reflect an effort to protect the "spontaneity of trial," in the belief that discovery and deliberate preparation to meet work-product materials may distort trial. In part, this doctrine reflects deeper concerns about the value of preserving a traditional adversary system. Our system remains genuinely adversary in much of the pretrial preparation process. It is overwhelmingly adversary in the trial process. Work-product doctrine responds to the need to fit the cooperative dimensions of discovery into this adversary framework. Discovery has not been pushed to the point of complete cooperation, nor to the point closest to attainable efficiency. This result suggests the continuing relevance of the most important questions regarding the role of discovery in an adversary system.

\section{F. Complete Sharing}

On the face of things, discovery is a remarkably awkward means of sharing information. It would be much easier and more efficient in some ways to require every party to produce voluntarily all the information available to it that may bear on the dispute. Why should we not require complete sharing, so that no one need go through the wasteful ritual of demand and response? And, with complete sharing, why should we not leave the costs of producing information on the party who has the information to produce?

Practical responses of course abound. One is that one party may not recognize the relevance of information useful to another. A second is that we cannot trust each party to admit that it recognizes the relevance of its information. An explicit demand can educate and can raise the stakes of concealment. A third is that there may be much more relevant information available to one party than any party needs or wants. Yet others surely exist.

Beyond these practical reasons, however, lie much more confused traditions. Rule 26(a) disclosure is limited, and may be discarded by local rule, court order, or agreement of the parties. We still do not require one party to reveal many varieties of critically important information until it is demanded. We impose an adversary burden of demanding it. If the adversary is too inept to seek the information, it is proper to maintain secrecy. A defendant who knows of three witnesses who will testify that the defendant ran a red light can seek judgment as a matter of law because the plaintiff has failed to follow through on any disclosure of their identities and has failed to produce any testimony that the light was red. Summary judgment can be sought on the ground that the plaintiff does not have any evidence that the light was red. 
These rules tie directly to the rules allocating trial burdens of production. We assign the plaintiff the burden of adducing evidence that the light was red. We do not require the defendant to help the plaintiff find that evidence, except as disclosure, discovery, and trial subpoenas may compel disclosure. And if the defendant does not have the information, even in the sense in which information is known to any part of a defendant organization, discovery cannot shift the burden of investigation to the defendant. Often we do not ask whether the defendant can acquire the information at lower cost-more efficiently-than the plaintiff. Relative ease of access to evidence is only one factor considered in allocating burdens, and even then it is considered only as a matter of general experience, not case-specific fact. Nor do we make a losing defendant pay the full costs incurred by the plaintiff in acquiring the information by investigation: even in the cases in which attorney fees are shifted, such costs as the time devoted to the litigation by the party go uncompensated.

Many trial burdens continue to be controlled by rules developed long before the emergence of modern discovery. Discovery has dramatically reallocated the costs of preparing for trial. There is no coherent theory to explain this effect of discovery. And there is no coherent theory that can help us think about the ways in which we should reallocate the costs of discovery. It has not been suggested that we should return closer to prediscovery days by imposing on the party who would have the trial burden of production on an issue the full costs of discovery compliance on that issue. Such an allocation would be incredibly confused when different parties have trial burdens on closely related issues: a sufficient illustration is the common allocation to the plaintiff of the burden of proving negligence and to the defendant of the burden of proving comparative negligence. More important, we may value discovery in part because it does shift part of the cost of preparation.

If trial burdens do not afford a comfortable guide to allocating the costs of discovery, we must confront a system that provides no other obvious guide. Equal sharing of the costs of reasonable discovery, imposing the costs of additional discovery on the demanding party, must confront an adversary system that makes no effort to allocate equally any of the other costs of litigation. Equal distribution can occur only by accident, not by the design of the system, and must be rare. There is no attempt to enforce symmetry in other costs. An attempt to enforce symmetry in discovery costs, even if it could be implemented, might improve matters if the natural asymmetry of discovery costs aggravates other asymmetries. There may be some intuitive ground for believing that parties who naturally bear a disproportionate share of discovery compliance costs also naturally bear a disproportionate share of other costs. Even if there is 
frequent coincidence as a general matter, individual cases will often depart from the general experience. Yet there is no apparent suggestion that we should attempt to tailor the allocation of discovery costs to reflect other asymmetries - the assumption, indeed, is that there are none-nor that we should attempt to allocate all other costs so as to achieve a predictable symmetry of all foreseeable litigation costs at each moment when settlement may be contemplated.

Perhaps it can be assumed that asymmetries of discovery costs generally aggravate other litigation cost asymmetries and that we can make rules that rely on general experience rather than case-specific facts. Before adopting cost allocation rules, we still must confront the question whether symmetry is the most important value. It may be better, as noted above, to treat the typical asymmetries as desirable: although the plaintiff must carry the burden of proving a product defective, the cost of gathering information about the product should be spread among all users as one of the costs of production and sale. If the need to bear these costs in discovery encourages the defendant to settle on terms that trade off discovery costs for a recovery greater than the expected value of the award at trial, the worst that can be said is that a litigating expense has been converted into a windfall for the plaintiff that all parties prefer to litigation. That is not a disastrous result. To the contrary, the result may be desirable because it compensates for differences in the risk averseness and bargaining power of the parties. To the extent that the expected value of the trial award is reduced below full compensation because of uncertainty as to the outcome, the settlement result may simply approach closer to full compensation. Occasional spectacular awards apart, there is little reason to believe that plaintiffs are systematically winning net overcompensation through judgment or settlement.

It may be possible to frame the question in a simple way. Let it be assumed that by allocating discovery compliance costs we could foster settlements that more accurately mirror the amount that would be awarded at trial. Although it is very easy to take trial judgment as the measure of justice, there are good reasons to doubt that measure. The amount that would be awarded at trial results from a system that does not allocate all costs equally. Settlement often is valued not because of efficiency but because it substitutes an "expected value" for the uncertain outcome of a real judgment. If all parties agree that there is a $\mathbf{0 . 5 0}$ probability of a $\$ 1,000,000$ judgment, and all of the other conditions are met, a $\$ 500,000$ settlement is rational and efficient. It substitutes for a judgment that might be zero, might be more than $\$ 1,000,000$, and might be somewhere in between. The chance that the judgment actually would be $\$ 500,000$ is vanishingly small. Yet many people regard the settlement 
as better justice because of doubts about the cogency of trial procedure and uncertainty as to the wisdom of underlying substantive principles. We do not expect that trials in fact always reach the results of "complete information." We may be skeptical about the random and unforeseeable character of errors. Even with complete information, moreover, trial of civil cases theoretically resolves uncertainty by awarding the $\$ 1,000,000$ if the tribunal is more than 0.50 certain that the plaintiff should prevail, and $\$ 0$ if the tribunal is no more than 0.50 certain. If the certainty levels are set accurately, many of these judgments will be completely wrong. Tribunals in fact often do not behave that way, preferring to resolve uncertainty by compromising the award of damages. Settlements reflect that behavior. Nonetheless, tribunals at times honor the all-or-nothing rules. The compromise of settlement may seem more just as well as more efficient. Tailoring discovery cost allocations to settlement must account for the intrinsic virtues of the settlement process as well as the dubious virtues of the trial process and trial-based judgments. 